Recebido em 02/2019. Aceito para publicação em 12/2019.

\title{
O ENSINO DE PORTUGUÊS EM CURSOS DE ENGENHARIAS E DE CIÊNCIA E TECNOLOGIA EM UNIVERSIDADES POTIGUARES: UMA DEMANDA POR UM ENSINO PARA FINS ESPECÍFICOS
}

\section{PORTUGUESE LANGUAGE TEACHING IN ENGINEERING AND SCIENCE AND TECHNOLOGY UNDERGRADUATE COURSES AT UNIVERSITIES IN RIO GRANDE DO NORTE: A DEMAND FOR A SPECIFIC-PURPOSE TEACHING}

\author{
Mário Martins ${ }^{1}$ \\ Maria Alice Sales ${ }^{2}$
}

Resumo: Na Resolução no 11/2002, do Conselho Nacional de Educação (BRASIL, 2002), que institui as diretrizes curriculares dos cursos de engenharias nas universidades brasileiras, estabelece-se que o egresso de um curso de engenharia deve saber comunicar-se de forma escrita e oral. Da perspectiva dos Letramentos Acadêmicos (LEA, 2017, LEA; STREET, 1998; 2006), em que se crê que o letramento é uma prática cultural e, portanto, diferenciada pelos contextos em que ocorre, é legítimo questionar como os cursos de engenharia das universidades federais potiguares satisfazem essa demanda legal. O objetivo deste trabalho, portanto, é analisar os modos de institucionalização do ensino de português nos cursos de engenharia dessas instituições e também no curso de bacharelado em ciência e tecnologia, como primeiro ciclo de algumas das engenharias. Para tanto, realizou-se uma análise documental dos projetos pedagógicos dos referidos cursos de três instituições federais localizadas no estado do Rio Grande do Norte. A análise centrou-se em particular na identificação e na caracterização das disciplinas ligadas ao ensino de português, a partir das seguintes unidades de análise: título, ementa e referências bibliográficas. Os resultados revelam que a maioria das disciplinas voltadas ao ensino de português fundamenta-se em abordagens generalistas, em que não se consideram as necessidades comunicativas especificas da profissão.

Palavras-chave: Português para fins específicos; letramentos acadêmicos; engenharias; ciência e tecnologia.

\begin{abstract}
In Resolution No. 11/2002, adopted by the National Council of Education (BRASIL, 2002), which establishes curricular guidelines for engineering courses in Brazilian universities, it is established that the recent graduate in Engineering must know how to communicate in written and oral forms. From the perspective of the academic literacies (LEA, 2017, LEA; STREET, 1998, 2006), in which literacy is believed to be a cultural practice and therefore differentiated by the contexts in which it occurs, it is reasonable to question how the engineering courses of the public universities in Rio Grande do Norte respond to this legal demand. The aim of this work, therefore, is to analyze the ways Portuguese teaching in Engineering courses, as well as in the baccalaureate Science and Technology course - since it is the first cycle of some of the Engineering courses -, is documented in these institutions. For that, a documentary analysis was conducted with the pedagogical projects of undergraduate courses of three federal institutions located in the state of Rio Grande do Norte (Brazil). The analysis focused in particular on the identification and characterization of the disciplines related to Portuguese language teaching, from the following units of analysis: title, syllabus and bibliographical references. The results show that most of the disciplines focused on Portuguese language teaching are based on generalist approaches, in which the specific communicative needs of this profession are not considered.
\end{abstract}

Keywords: Portuguese for specific purposes; academic literacies; engineering; science and technology.

\footnotetext{
1 Docente de Língua Portuguesa e Linguística, Universidade Federal Rural do Semi-Árido, Brasil. E-mail: mgcmartins@gmail.com.

2 Discente do curso de Licenciatura em Letras-Português, Universidade Federal Rural do Semi-Árido, Brasil. Email: alicesales.nascimento@hotmail.com.
} 


\section{INTRODUÇÃO}

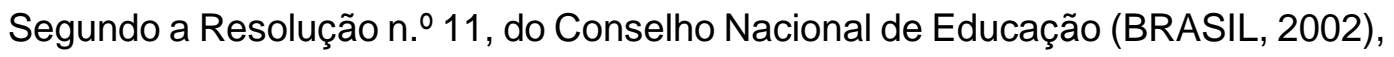
que institui as diretrizes curriculares dos cursos de engenharias, no artigo $4^{\circ}$, das competências e habilidades gerais necessárias aos egressos, lê-se que o engenheiro deve "comunicar-se eficientemente nas formas escrita, oral e gráfica" para a atuação em sua carreira. Desse modo, e considerando o aspecto escrito e oral em particular, é de responsabilidade das instituições de ensino superior instrumentalizar os futuros engenheiros com conhecimentos linguísticos que sejam orientados para as necessidades que essa carreira impõe. Disso surge a inquietação deste artigo: as universidades federais públicas potiguares satisfazem essa demanda?

Para responder a essa pergunta, no presente trabalho, são analisados os projetos pedagógicos dos cursos de engenharias de três instituições públicas de ensino superior localizadas no estado do Rio Grande do Norte: Universidade Federal Rural do SemiÁrido (UFERSA), Universidade Federal do Rio Grande do Norte (UFRN) e Instituto Federal de Educação, Ciência e Tecnologia do Rio Grande do Norte (IFRN). Além desses cursos, também se analisa o PPC do curso de bacharelado em Ciência e Tecnologia da UFERSA e da UFRN, por ser esse bacharelado a etapa inicial obrigatória para o seguimento em grande parte das engenharias dessas universidades.

Pretende-se, com essa análise, realizar um diagnóstico rigoroso dos modos como está institucionalizado o ensino da língua portuguesa nesses cursos, buscando observar também a orientação desse ensino: se pela perspectiva do português instrumental, que implica uma abordagem mais geral sobre a língua e se enquadra em todo o tipo de curso superior, ou se orientado pela perspectiva do português para fins específicos, que, como defendido por Cintra e Passarelli (2008, apud LACERDA; SOUSA; SILVA, 2014, p. 247), significa uma abordagem de ensino-aprendizado do português voltado para propósitos ou para áreas de atuação específicos, contribuindo para a construção de novos modos de agir e de pensar do aprendiz.

O português para fins específicos, parafraseando-se uma definição de Hyland (2007, p. 379) para a expressão correlata em inglês (English for Specific Purposes), refere-se às pesquisas e ao ensino que enfocam as necessidades e as práticas comunicativas específicas de determinados grupos sociais, dentre eles, grupos acadêmicos e profissionais. Neste artigo, centrado na realidade de cursos de engenharias e de ciência e tecnologia, discute-se tanto o aspecto acadêmico, como o aspecto profissional no ensino de português para fins específicos no contexto da formação universitária.

Segundo Lacerda, Sousa e Silva (2014, p. 247), o ensino de português para fins específicos é fundamentado na importância de que tal conhecimento prepara funcionalmente o aprendiz para lidar com as demandas linguísticas que esse aprendiz de fato necessita satisfazer em diferentes contextos comunicativos. No entanto, ainda conforme os autores, o ensino-aprendizagem de português para fins específicos é uma 
área de pesquisa ainda muito recente no Brasil. Por esse fato ainda são raros os trabalhos relacionados a essa perspectiva de ensino em campos profissionais particulares, o que também se aplica às engenharias.

A análise aqui proposta, focada na realidade de três universidades públicas potiguares, orienta-se por posturas teóricas vinculadas aos estudos dos novos letramentos, a partir dos quais se entende o letramento como uma prática social, que é variável de um contexto a outro e em que os sujeitos envolvidos compreendem os significados das suas ações de modos distintos, sendo tais significados resultantes não de processos individuais ou cognitivos, mas de processos culturais (STREET, 2009, p. 138). Desse modo, justifica-se considerar o contexto específico potiguar e ainda considerar que cada uma dessas universidades também se conforma por cenários mais específicos ainda.

Adotou-se como procedimento metodológico a análise documental dos projetos pedagógicos dos referidos cursos, centrada na identificação e na caracterização das disciplinas ligadas ao ensino de português, a partir das seguintes unidades de análise: título, ementa e referências bibliográficas. Por esses elementos, tentou-se identificar a abordagem de cada disciplina e consequentemente enquadrá-la em uma das seguintes perspectivas de ensino: português instrumental ou português para fins específicos.

Nas seções que seguem, primeiramente discute-se o conceito de letramento acadêmico, enquanto campo heterogêneo que tem repercussões na vida do estudante universitário. De forma contínua, trata-se da perspectiva de ensino de línguas para fins específicos. Depois de apresentados os procedimentos metodológicos, apresentam-se e discutem-se os resultados, seguidos das considerações finais.

\section{Letramentos acadêmicos: uma forma de reconfigurar a formação linguística na universidade}

Entende-se aqui o letramento acadêmico como um campo de pesquisas que pode influenciar nas didáticas de ensino relacionadas às formas de utilização da língua. A definição de letramento acadêmico pode variar a depender da visão do autor. Alguns autores, como Marinho (2010), compreendem o letramento acadêmico como produção e interpretação de textos no contexto universitário, afirmando que:

Leitura e a escrita de gêneros de referência na academia - artigos, teses, monografias, dissertações, resenhas acadêmicas, entre outros - são realizadas, de preferência, na universidade, porque é nessa instituição que são produzidos, por necessidades próprias, esses gêneros (MARINHO, 2010, p. 366).

Já de acordo com Lea e Street (2014), entendimento que aqui se adota, o letramento acadêmico vai além dessa perspectiva. Os autores observam as práticas sociais que envolvem leitura e interpretação de texto, afirmando que é necessário observar as práticas de letramento de acordo com a situação comunicativa, adequando- 
as de acordo com o contexto. Os autores discutem três abordagens possíveis para o tratamento do letramento acadêmico, ou modelos: o modelo das habilidades de estudo, o modelo da socialização e o modelo dos letramentos acadêmicos, defendido por tais autores.

No modelo das habilidades de estudo, entende-se que a escrita, e o letramento consequentemente, se instancia a partir de um conjunto de habilidades cognitivas que os discentes individualmente possuem, pelo que são capazes de ajustar essas habilidades em diferentes domínios discursivos, de acordo com as suas configurações específicas. É um modelo de análise centrado na superfície textual, em que questões de natureza estrutural da língua constituem o foco da atenção.

O modelo da socialização acadêmica considera que o letramento é, acima de tudo, um processo de adaptação dos aprendizes numa dada cultura acadêmica, um processo de aculturação, portanto, que se realiza por meio de configurações discursivas dependentes de campos epistemológicos específicos e dos modos como se institucionalizam nessas áreas de conhecimento, através de disciplinas, projetos de pesquisa, etc.

O modelo dos letramentos acadêmicos, como proposto por Lea e Street (2014), engloba esses dois modelos, mas extrapola-os, considerando questões de natureza social para entender as práticas universitárias. Partindo desse ponto de vista, os letramentos acadêmicos não se resumem à produção escrita e à leitura restritas às disciplinas, mas englobam essas competências em outras áreas do conhecimento. Segundo Lea e Street,

O modelo de letramentos acadêmicos vai além, ao focalizar a relação entre epistemologia e escrita não apenas na área temática geral, mas também, mais amplamente, nas exigências institucionais, bem como em contextos mais específicos como variação em função de exigências individuais (LEA; STREET, 2014, p. 479).

Desse modo, a leitura e a escrita em contexto universitário devem ser vistos como ferramentas sociais dentro da academia, pois os discentes utilizam-se dessas competências adequando a sua escrita de acordo com o que é exigido, ou seja, dependendo do contexto em que é inserido. Para Lea e Street (2014, p. 478), o objetivo dessa abordagem "é dispor de modo conjunto de práticas de letramento apropriadas a cada cenário e lidar com sentidos sociais e identidades que cada prática evoca."

Por conseguinte, pode-se compreender que a abordagem dos letramentos acadêmicos tem a preocupação de que os discentes possam ter conhecimento de competências que são exigidas em diversos contextos. Também deve-se compreender que disciplinas relacionadas aos letramentos são necessárias nos cursos de graduação, pois muitos alunos chegam ao ensino superior sem o conhecimento de gêneros necessários na academia. Cunha (2012, p. 132) afirma que os estudantes que 
ingressam nesse meio acadêmico não possuem conhecimento de gêneros como: "fichamento, resenha, resumo, gráficos, diagramas, fluxogramas, etc."

Em linha com Ribeiro, Guimarães e Silva (2012 p. 119), é necessário que o aluno aprenda "formas de falar, ouvir, escrever, ler etc. específicas do contexto acadêmico, o que não acontece de forma imediata, mas ao longo do percurso estudantil." Porém, é importante observar o curso em que o aluno está inserido, pois a língua não é homogênea e varia de acordo com o contexto comunicativo, ou seja, cada curso vai fazer uso de habilidades linguísticas de formas distintas.

Outro ponto colocado em discussão é que, independentemente do curso, o aluno deve ir além das competências orais e escritas, pois, como afirmam Heinig e Franzen (2013, p. 9),

Vivemos em uma sociedade grafocêntrica, permeada pela cultura escrita. Contudo, não basta saber ler e escrever para fazer parte dessa sociedade. É preciso ir além, saber interagir em práticas de letramento nos diferentes campos de atuação; saber fazer uso da leitura e da escrita, levando em conta o contexto, a situação e a cultura de cada espaço social.

Mediante o que foi exposto, é possível perceber a importância das diferentes - e por que não dizer complementares - perspectivas dos letramentos para um campo de pesquisa que repercute nas didáticas de ensinos que o docente utiliza. Os letramentos são práticas transformativas, que observam a leitura e a escrita em vários contextos, sendo afetadas por várias dimensões.

\section{Ensino de línguas para fins específicos: uma proposta para um letramento acadêmico eficiente}

A história do ensino de língua portuguesa em cursos universitários tem suas origens com a perspectiva do português instrumental, uma abordagem de ensino implantada no Brasil na década de 80. O português instrumental trabalha em geral com redações técnicas, científicas e literárias, noções sobre texto, dissertações e outras técnicas que envolvem leitura e interpretação de texto. É, portanto, uma abordagem generalizante da língua, que desconsidera as necessidades específicas dos cursistas. Por essa razão, pode-se afirmar que "português instrumental" não é uma expressão sinônima de "português para fins específicos".

O ensino de línguas para fins específicos, enquanto perspectiva de ensino orientada para o uso da língua de acordo com as necessidades comunicativas do falante, tem uma história mais recente, francamente inspirada por práticas do cenário anglófono, em que é moeda corrente. Segundo Guimarães (2014), essa perspectiva começou a ser utilizada no Reino Unido, sendo implantada primeiramente para estudantes que não tinham o inglês como primeira língua. Posteriormente, o ensino de língua inglesa com fins específicos passou a ser utilizado também com falantes nativos, 
considerando os seus contextos comunicativos e profissionais. Com o advento do mercado de trabalho mais globalizado, para o qual os profissionais devem ter competências comunicativas diversificadas, o ensino de língua com fins específicos passou a ser uma realidade noutras línguas, inclusive na língua portuguesa, trazida à discussão no Brasil, por exemplo, por Cintra e Passarelli (2008, apud LACERDA; SOUSA; SILVA, 2014, p. 247).

A especificidade, nesse contexto, justifica-se na compreensão de que as esferas discursivas diferem umas das outras tanto na dimensão social como na dimensão cognitiva, o que se vê não somente nos campos de conhecimento, mas também nos modos como se realizam a fala, a estrutura retórica, os comportamentos sociais, as relações de poder e os interesses políticos (HYLAND; HAMP-LYONS 2002, apud LONG, 2005, p. 2). O ensino de línguas para fins específicos opõe-se ao ensino de línguas para fins gerais, que, de acordo com Long (2005, p. 1), ao serem formulados com programas e materiais genéricos, são ineficientes e inadequados. Ao contrário disso, o ensino de línguas para fins específicos permite estimular habilidades de escrita e leitura adequadas a contextos de ocorrência, o que configura esse tipo de ensino como uma faceta possível da abordagem dos letramentos acadêmicos.

O entendimento que se tem dessa especificidade no contexto do ensino de línguas fundamenta-se num conjunto de premissas. A primeira delas é a de que os eventos comunicativos em contextos particulares, como acadêmicos ou profissionais, ocorrem em número limitado. A segunda premissa, consequência da primeira, é a de que esses eventos são recorrentes. Por serem recorrentes e em número limitado, o uso da língua em contextos específicos é previsível, o que é a terceira premissa. Por meio da perspectiva didático-metodológica do ensino de línguas para fins específicos, o discente é exposto aos eventos comunicativos próprios da sua área de conhecimento ainda no percurso da sua formação universitária. Torna-se legítimo, portanto, o objetivo desta pesquisa, que é examinar se - e como - essa abordagem de ensino está sendo efetivada nos cursos de engenharias e ciência e tecnologia das instituições de ensino superior federais (UFERSA, IFRN e UFRN) localizadas no Rio Grande do Norte.

\section{METODOLOGIA}

Neste trabalho, adotou-se como procedimento metodológico a análise documental. Podemos entendê-la de acordo com Richardson et al (1999, p. 230 apud GARCIA JÚNIOR; ALVES; MEDEIROS, 2017, p. 141) como "uma série de operações que visam estudar documentos no intuito de compreender circunstâncias sociais e econômicas". Assim podemos entender que:

Organizar o material significa processar a leitura segundo critérios da análise de conteúdo, comportando algumas técnicas, tais como fichamento, levantamento quantitativo e qualitativo de termos e assuntos recorrentes, criação de códigos para facilitar o controle e manuseio. (PIMENTEL, 2001, p. 184). 
Para o efeito pretendido, primeiramente foram selecionados os projetos pedagógicos de cursos (doravante, PPC) de Engenharias das três universidades públicas potiguares. O PPC é um documento elaborado pela universidade, tendo em vista as Diretrizes Curriculares Nacionais de cada curso. Nele podemos encontrar informações sobre a expectativa de formação do aluno, os campos de atuação, além das disciplinas (optativas e obrigatórias) que compõem o curso com suas respectivas ementas. Os PPC foram extraídos das páginas eletrônicas oficiais mantidas pelos cursos em questão.

Em seguida, foram identificadas nos PPC as disciplinas relativas ao ensino de Português. Esse procedimento amparou-se no sistema de busca a partir de descritores, que foram (língua, linguagem, português, leitura, escrita, texto, resenha, resumo, relatório técnico, projeto de pesquisa), optamos por estas, por serem próprias do ensino de língua portuguesa. Foram excluídos da análise os cursos que não contemplavam o ensino de português.

Tendo sido identificadas as disciplinas relativas ao ensino de português, passouse à fase da análise propriamente, a partir da qual foi possível dividir os cursos em duas categorias, semelhante ao que fazem Lacerda, Sousa e Silva (2014): i) os que têm disciplinas orientadas pela perspectiva do português instrumental; e ii) os que têm disciplinas orientadas para o ensino de português de forma específica, em que se consideram práticas acadêmicas e profissionais dos engenheiros. Para a identificação da perspectiva de ensino, estabeleceram-se como categorias de análise três das partes constitutivas dos componentes curriculares, a saber: títulos, ementas e referências bibliográficas. É importante observar que o próprio título da disciplina já indica se está ou não relacionada ao ensino da língua. $\mathrm{Na}$ ementa podemos identificar qual o objetivo da disciplina e observar se as habilidades referentes ao ensino de português são voltadas para um viés instrumental ou específico, o que se confirma com as referências bibliográficas.

\section{Análise e discussão dos resultados}

\subsection{Universidade Federal Rural do Semi-Árido (UFERSA)}

Da Universidade Federal Rural do Semi-Árido (UFERSA), foram examinados os projetos pedagógicos de doze cursos de engenharias: Agrícola e Ambiental, Ambiental e Sanitária, Civil, Elétrica, Florestal, Mecânica, Química, de Computação, de Energia, de Pesca, de Petróleo, de Produção, além do curso de Ciência e Tecnologia. As engenharias Agrícola e Ambiental, de Pesca e Florestal são cursos de $1^{\circ}$ ciclo, isto é, o acesso acontece por meio do SISU. Todas as outras engenharias constituem cursos de $2^{\circ}$ ciclo, pelo que é obrigatória primeiramente a realização do Bacharelado em Ciência e Tecnologia, cujo PPC também foi examinado.

Identificou-se, nos cursos de Ciência e Tecnologia, formação de base de outras engenharias, e no curso de Engenharia Agrícola e Ambiental, uma disciplina voltada para o português, que se intitula Análise e Expressão Textual, de caráter obrigatório, 
com carga horária de 60 horas. As engenharias de Pesca e Florestal não possuem disciplinas voltadas ao estudo da língua portuguesa. Também, nenhuma das engenharias de $2^{\circ}$ ciclo exige, em seus PPC, disciplinas de português, o que aparentemente se justifica no fato de os seus alunos já terem passado pelo curso de Ciência e Tecnologia.

A ementa de Análise e Expressão Textual, do curso de Ciência e Tecnologia e das engenharias Agrícola e Ambiental, propõe aos discentes uma abordagem propedêutica de gêneros textuais e técnicas de estudo relativos à esfera acadêmicocientífica, com o aprendizado de fichamentos, resenhas, resumos, por exemplo. Essa leitura se corrobora por duas das indicações bibliográficas: Redação Científica, de João Bosco Medeiros, e Metodologia do Trabalho Científico, de Antonio Joaquim Severino. Sem o mesmo caráter científico-acadêmico, outra obra é sugerida nas referências básicas dessa disciplina: Português Instrumental, Dileta Silveira Martins e Lúbia Scliar Zilberknop, uma obra generalista, que trata de questões relacionadas à comunicação oral e escrita que podem ser aplicadas a vários campos de saber, das engenharias à medicina, pois que aborda temas como estilo, parágrafos, frases e discursos ou ainda tipologias textuais, como narração, dissertação e descrição, incluindo-se gêneros vários, como ofício, ata ou carta comercial. O alcance da obra é tal que discorre também sobre aspectos ortográficos, gramaticais e nomenclaturais da língua portuguesa. A disciplina de Análise e Expressão Textual também se utiliza de um material denominado Metodologia Científica: uma abordagem direcionada para os cursos de engenharia, mas a que os pesquisadores não conseguiram ter acesso, apesar de uma busca rigorosa na internet.

A disciplina de Análise e Expressão Textual, ofertada pela UFERSA para os cursos de Ciência e Tecnologia e Engenharia Agrícola e Engenharia Ambiental, tenta ser uma aproximação dos alunos com as práticas de letramento recorrentes no universo acadêmico. Isso é perceptível na verificação tanto da ementa da disciplina, como nas suas obras basilares. No entanto, a preocupação com um português geral, amplo, independente de contextos de uso ainda se mantém presente, o que parece ser um reflexo, como se vê no PPC do curso de Ciência e Tecnologia (UFERSA, 2010, p. 20), de uma "constante inquietação dentro das universidades [...] quanto à carência na formação básica dos discentes. Trata-se de uma posição consensual a deficiência principalmente em Língua Portuguesa [...], o que dificulta o processo ensinoaprendizagem."

Corrobora a leitura de que a disciplina acima descrita ainda não se enquadra plenamente no perfil de uma disciplina específica o vácuo deixado quanto às práticas de linguagem profissionais específicas da área das engenharias. Não há, pelo menos como diretriz legal, qualquer indicação de estudo, por exemplo, sobre relatórios técnicos, gênero incontornável de muitas engenharias. Vale destacar também que as obras bibliográficas complementares destoam da realidade dos engenheiros, de que se 
pode citar O texto na sala de aula - leitura e produção, João Wanderley Geraldi, obra imprescindível para alunos de Letras.

Embora se note a preocupação com as práticas de letramento acadêmico da única disciplina da UFERSA oferecida aos discentes dos cursos de ciência e tecnologia e engenharias para se aproximar de uma diretriz mais atual, cenário recorrente hoje em muitos desses cursos, como lembram Ribeiro e Villela (2010, apud RIBEIRO; GUIMARÃES; SILVA, 2012, p. 118) identifica-se que a disciplina ainda não possui um ensino de cunho específico, guardando princípios e práticas de ensino de um português instrumental, generalista, o que se corrobora com as referências bibliográficas.

\subsection{Universidade Federal do Rio Grande do Norte (UFRN)}

Quanto à Universidade Federal do Rio Grande do Norte (UFRN), foram analisados os títulos, as ementas e as referências bibliográficas nos PPC de dezessete cursos de engenharias: Aquicultura, Têxtil, de Petróleo, Mecatrônica, Computação, de Telecomunicação, de Alimentos, de Materiais, Biomédica, de Produção, Florestal, de Software, Elétrica, Civil, Ambiental, Química e Mecânica. Além disso, analisou-se também o PPC do curso de Ciência e Tecnologia, visto que o referido curso, como na UFERSA, é pré-requisito para o ingresso em algumas das engenharias: Ambiental, Biomédica, de Materiais, de Petróleo, de Telecomunicação, de Computação, Mecânica e Mecatrônica.

Identificaram-se, nos cursos de Ciência e Tecnologia e de Engenharia de Software, duas disciplinas relacionadas à língua portuguesa: Práticas de Leitura e Escrita I e Práticas de Leitura e Escrita II, cada uma com carga horária de 30h. Elas fazem parte do núcleo de formação obrigatória. A partir da análise da ementa da primeira disciplina, nota-se que há uma explícita vocação para questões de texto, em que se enfatizam noções de gêneros discursivos, coesão e coerência, paragrafação, segmentação textual, inferências. Parece, portanto, uma disciplina orientada para a formação de escritores/leitores conscientes do texto e de suas especificidades, não possuindo quaisquer especificidades em relação à configuração do curso a que está associada. Julgamos, portanto, que se trata de uma disciplina de caráter mais generalista. Vale ressaltar que, entre as suas referências básicas, constam Curso de redação, de Antonio Suarez Abreu, e A coesão textual, de Ingedore Grunfeld Villaça Koch, livros que tipicamente circulam entre estudantes de Letras e professores de português.

Na Prática de Leitura e Escrita II, embora se leia na ementa que é uma disciplina centrada em "Práticas de leitura e escrita na área de ciências tecnológicas e exatas" (UFRN, 2017, p. 113), nada nas referências bibliográficas deixa ver algum foco específico dessa área de conhecimento. As muitas referências - 10 básicas e 22 complementares - são bastante coerentes com outros pontos da ementa, tais como estratégias de argumentação, gêneros discursivos, com ênfase no artigo de opinião e na carta argumentativa, ou questões gramaticais. Constam das referências obras como 
A arte de argumentar, de Antonio Suarez Abreu, Pensamento crítico: o poder da lógica e da argumentação, de Walter Carnielli e Richard Epstein, e Gramática reflexiva: texto, semântica e interação, de William Roberto Cereja e Thereza Cochar Magalhães, de indicação recorrente em espaços da Educação Básica. Nota-se, pela leitura dos documentos oficiais, que não há, nessas disciplinas obrigatórias do curso de Ciência e Tecnologia da UFRN, qualquer foco para a escrita acadêmica. E, semelhantemente ao que acontece na UFERSA, também não se documentam os gêneros que os egressos do curso possam vir a utilizar na atuação profissional. Portanto, é uma disciplina que se aproxima mais de uma abordagem instrumental.

Vale destacar que há disciplinas optativas que parecem preencher parcialmente essas lacunas. Uma delas é Práticas de Leitura e Escrita de Gêneros Acadêmicos, de 60 horas-aula. É, portanto, uma disciplina centrada no aprendizado de gêneros acadêmicos (projeto de pesquisa, resenha, resumo, ensaio, artigo de divulgação científica), referências bibliográficas básicas correspondentes, entre elas Resumo, Resenha, Planejar textos acadêmicos e Trabalhos de pesquisa: diários de leitura para a revisão bibliográfica, todas as quatro obras de autoria de Anna Rachel Machado, Eliane. Lousada e Lilia Santos Abreu-Tardelli.

A outra disciplina orientada para um fim específico é a optativa Práticas de Leitura e Escrita de Gêneros da Esfera Profissional, com 45 horas-aula. Compõe-se com foco na leitura e na escrita de gêneros circulantes na esfera profissional, tais como currículo, carta comercial, memorando, ata, relatório técnico e contrato, considerando seus aspectos conceituais, estruturais e estilísticos. Porém, apenas uma indicação bibliográfica aponta para a especificidade que a disciplina defende: Visitas técnicas: interação escola-empresa, de Anselmo Pereira de Lima, sendo todas as outras indicações genéricas, que, portanto, se aplicariam a qualquer curso, de qualquer área de conhecimento, como, por exemplo, Lógica e linguagem cotidiana: verdade, coerência, comunicação, argumentação, de Nílson José Machado e Marisa Ortegoza da Cunha, ou Problemas de redação, de Alcir Pécora. Essa disciplina optativa, embora não se ampare em referências bibliográficas específicas, tem na sua ementa um foco nas práticas de letramento da área das ciências e tecnologias, com gêneros frequentes na profissão de engenheiros, por esse motivo se aproxima de uma disciplina de português para fins específicos.

Vale a pena referir ainda que o curso de Engenharia Têxtil tem em seu PPC uma disciplina optativa vinculada à língua portuguesa, que é Prática de Leitura e Produção de Texto, uma disciplina de 60 horas-aula que conta "com ênfase em textualidade e tipologia". No referido PPC, não se encontram indicações bibliográficas para essa disciplina. Mesmo não tendo sido possível realizar o mesmo procedimento de análise, pela ementa revela-se com uma abordagem generalista, portanto instrumental.

As engenharias de Alimentos, de Aquicultura, de Produção, Elétrica, Química e Florestal, cujo ingresso se dá pelo SISU, não têm disciplinas voltadas para o estudo de 
Português. Como acontece com a UFERSA, os cursos de engenharia da UFRN de $2^{\circ}$ ciclo, isto é, os que exigem o curso de Ciência e Tecnologia como pré-requisito, também não possuem disciplinas de português.

\subsection{Instituto Federal de Educação, Ciência e Tecnologia do Rio Grande do Norte (IFRN)}

No Instituto Federal do Rio Grande do Norte (IFRN), é ofertado apenas um curso de engenharia, que é a Engenharia de Energia. No PPC desse curso, identificou-se a disciplina de Leitura e Produção de Textos Acadêmicos, com carga horária de 60h, em que, pela ementa, há o estudo do texto, "com ênfase em aspectos organizacionais do texto escrito e oral de natureza técnica, científica e/ou acadêmica (IFRN, 2015, p. 71). Embora programas das disciplinas não tenham sido aqui utilizados como escopo de análise, no caso dessa disciplina, nota-se a sua vocação para o ensino com fins específicos acadêmicos, pois que se encontram entre os tópicos de ensino questões como resumo, resenha, artigo científico e ainda convenções da ABNT. A disciplina da engenharia do IFRN diferencia-se das outras aqui discutidas por tratar de questões pertinentes ao processo de compreensão da autoria (ou de voz autoral), como juízos de valor e discurso alheio, e ainda por referir as modalidades escrita e falada em contraponto, abrindo um espaço para a discussão do gênero acadêmico oral seminário. À exceção de três indicações bibliográficas, as já citadas Resumo e Resenha e ainda Manual de artigos científicos, de Hortência de Abreu Gonçalves, nada há que aponte para o estudo de textos no contexto específico da profissão de engenheiro. Apesar disso, e pela configuração orientada para as práticas de letramento acadêmico, classifica-se esta disciplina como dentro de um escopo da abordagem específica.

\section{Algumas reflexões}

A partir dos resultados da análise documental apresentada anteriormente, em que se identificou que há uma frequência bastante restrita de disciplinas obrigatórias relacionadas ao ensino de português nos PPC dos cursos analisados - além de se conformarem maioritariamente como generalistas -, levantam-se aqui três fatores possíveis, estando eles inter-relacionados.

Um primeiro fator que pode explicar a oferta de disciplinas generalistas de leitura e produção textual nos cursos de engenharia e ciência e tecnologia reside na concepção bastante difundida de que a maioria dos calouros nas universidades têm dificuldades linguísticas, nomeadamente de leitura e escrita. Logo, entende-se que as disciplinas vinculadas à leitura e à produção de textos aparentemente tornam-se uma tentativa institucionalizada de reparar danos. Do mesmo modo como Fiad (2011, p. 360), posicionamo-nos contra esse "discurso da crise", em que se costumar ecoar que alunos universitários não sabem ler ou escrever ou que a escola não lhes foi útil. Acreditamos que a entrada na universidade marca um momento de mudanças de práticas de letramento, com diferentes gêneros de texto e, consequentemente, com diferentes 
formas de materialização tanto linguísticas, como discursivo-pragmáticas, sendo tais práticas de circulação maioritariamente restrita ao ambiente acadêmico - a prática institucional do mistério, nas palavras de Lillis (1999, p. 127).

Não se ignora obviamente que as práticas textuais acadêmicas são tratadas superficialmente (ou mesmo ignoradas) no percurso da escolarização básica, mas, no espaço da universidade, é preciso refletir sobre estratégias de engajamento dos alunos nessas práticas, que se constituem como um conjunto complexo, contextualmente baseadas (GOURLAY, 2009). Não fazê-lo é somente perpetuar a crise. Assumir a abordagem dos letramentos acadêmicos, como proposto por Lea (2017) e Lea e Street (1998; 2006), torna-se particularmente adequado para compreender o espaço universitário brasileiro, em que se veem mudanças significativas, nos últimos anos, do perfil socioeconômico dos alunos, resultado de políticas de democratização de acesso (FONAPRACE, 2014).

Um segundo fator diz respeito ao também senso comum de que a engenharia é uma área de conhecimento matemático unicamente, de cálculos. Nesse contexto, parece ser a língua reduzida a objeto de ensino unicamente (e, pelo que se viu em muitos dos PPC analisados, reduzida a questões pontuais da produção textual). Assim, parece ignorar-se que a língua é ela própria é um instrumento da aprendizagem, até mesmo na aula de Cálculos. Em resposta ao questionário de avaliação do ENADE de 2005, a técnica de ensino mais usadas por docentes de Engenharia, na percepção dos estudantes, é a aula expositiva e que a prova escrita discursiva é o instrumento de avaliação mais usado pelos professores (OLIVEIRA, 2010).

Retome-se ainda a própria Resolução no 11/2002, do Conselho Nacional de Educação (BRASIL, 2002), que, no artigo 4ํㅜㄹ afirma ser necessário que o engenheiro adquira a capacidade de "comunicar-se eficientemente nas formas escrita, oral e gráfica" para a atuação em sua carreira. Obviamente, um engenheiro (ou estudante de engenharia) faz uso, em diversos momentos, de formas de comunicação específicas dentro da universidade e na sua vida profissional. Sem entrar nas razões mais basilares de uma aprendizagem satisfatória da língua para uma cidadania plena - moeda já corrente no campo dos estudos da linguagem -, lembra-se aqui da necessidade profissional de engenheiros, que, de acordo com a Resolução 1.010, do Conselho Federal de Engenharia, Arquitetura e Agronomia (CONFEA, 2005), necessita de competências linguísticas (e de conhecimento sobre os gêneros textuais correspondentes) para se envolver em diversas das suas atividades, tais como a realização de laudos, de pareceres técnicos, divulgação técnica, além de competências para o ensino e para a pesquisa.

O terceiro fator, que em especial se liga à ausência de disciplinas vinculadas ao ensino de português para fins específicos, pode ser tanto interpretado como uma consequência dos dois primeiros, como uma causa. Trata-se da ausência de materiais didáticos e investigativos em português (e para o português) que sejam afiliados à 
perspectiva de ensino para fins específicos. Ao contrário do que acontece no cenário anglófono, em que há décadas existe o desenvolvimento sistemático de teorias e práticas inovadoras para a compreensão de diversas formas em que a língua é usada em comunidades específicas (HYLAND, 2007), no caso brasileiro ainda são poucas as pesquisas sobre ensino de português para fins específicos (embora nos últimos anos tenha surgido um interesse crescente), menor ainda é a disponibilidade de materiais didáticos de amplo alcance. As discussões que se apresentaram neste artigo pretendem ser um subsídio para o incremento desse cenário.

\section{REFERÊNCIAS}

BRASIL. Ministério da Educação - MEC. Conselho Nacional de Educação - CNE. Resolução CNE/CES 11, de 11 de março de 2002. Diretrizes Curriculares Nacionais dos Cursos de Engenharia. Brasília, 2002. Disponível em: http://portal.mec.gov.br/cne/arquivos/pdf/CES112002.pdf. Acesso em: 30 jan. 2019.

CONFEA. Resolução no $\mathbf{1 . 0 1 0}$, de 22 de agosto de 2005. Regulamenta as atribuições profissionais inseridas nos sistemas Confea/Crea. Disponível em:

http://www.confea.org.br/. Acesso em: 30 jan. 2019.

CUNHA, J. F. Letramento Acadêmico: Reflexão e Algumas Considerações sobre Cursos de Negócios em Faculdades Privadas Populares. Signum, v. 2, n. 15, p.129151, 2012.

FIAD, R. S. A escrita na universidade. Revista da ABRALIN, v. 10, n. 4, p. 357-369. 2a. parte, 2011.

FONAPRACE (Fórum Nacional de Pró-Reitores de Assuntos Comunitários e Estudantis. IV Pesquisa do perfil do socioeconômico e cultural dos estudantes de graduação das instituições federais de ensino superior brasileiras. Brasília: Fonaprace, 291 p. 2014.

GARCIA JUNIOR, E. F.; ALVES, C. A. L.; MEDEIROS, S. Análise documental: uma metodologia da pesquisa para a Ciência da Informação, Temática, v. 1, n. 7, p. 138150, 2017.

GOURLAY, L. Threshold practices: Becoming a student through academic literacies. London Review of Education, v. 7, n. 2, p. 181-192, 2009.

GUIMARÃES, R. M. O Ensino de Línguas para fins específicos (ELFE) no Brasil e no Mundo: Ontem e Hoje. Revista HELB: História do Ensino de Línguas no Brasil, v. 8, p. 1-10, 2014.

HEINIG, O. L. O. M.; FRANZEN, B. A. A leitura e a escrita na engenharia: construindo intersecções entre o mundo do trabalho e a academia. Revista de Ensino de

Engenharia, v. 32, n. 2, p. 10-18, 2013.

HYLAND, K. English for Specific Purposes: some influences and impacts. In: CUMMINS, J.; DAVIDSON, C. International Handbook of English Language Teaching. Nova York: Springer, 2007, p. 391-399. 
IFRN. Projeto Pedagógico do Curso de Bacharelado em Engenharia de Energia. Natal, 2017. Disponível em: http://portal.ifrn.edu.br/ensino/cursos/cursos-degraduacao/engenharias/engenharia-de-energia/view. Acesso em: 10 jan. 2019.

LACERDA, N. A.; SOUSA, M. A.; SILVA, M. T. M. Ensino de português para fins específicos: uma análise curricular em projetos pedagógicos de cursos de graduação da UFPI. In: JORNADA NACIONAL DO GELNE, 25., 2014, Natal. Anais... Natal: EDUFRN, 2014, p. 246-254.

LEA, M. R. Academic Literacies in Theory and Practice. In: STREET, B. V.; MAY, S. Literacies and Language Education. Cham: Springer, 2017, p. 147-158.

LEA, M. R.; STREET, B. V. O modelo de "letramentos acadêmicos": teoria e aplicações. Filologia e Linguística Portuguesa, v. 16, n. 2, p. 477-493, 2014.

LEA, M. R.; STREET, B. V. The "Academic Literacies" model: theory and applications. Theory into Practice, v. 45, n. 4, p. 368-377, 2006.

LEA, M. R.; STREET, B. V. Student writing in higher education: an academic literacies approach. Studies in Higher Education. v. 23, n. 2, p. 157-16, 1998.

LILLIS, T. Whose "Common Sense"? Essayist literacy and the institutional practice of mystery. In: JONES, C.; TURNER, J.; STREET, B. (Org.). Students writing in the university: cultural and epistemological issues. Amsterdam: John Benjamins, 1999. p. 127-140.

LONG, M. Second Language Needs Analysis. Cambridge: Cambridge University, 2005.

MARINHO, M. A escrita nas práticas de letramento acadêmico. Revista Brasileira de Linguística Aplicada, v. 10, n. 2, p.363-386, 2010.

OLIVEIRA, V. F. (Org). Trajetória e estado da arte da formação em Engenharia, Arquitetura e Agronomia - volume I: Engenharias. Brasília: Instituto Nacional de Estudos e Pesquisas Educacionais Anísio Teixeira, Conselho Federal de Engenharia, Arquitetura e Agronomia, 2010.

PIMENTEL, A. O método da análise documental: seu uso numa pesquisa historiográfica. Cadernos de Pesquisa, São Paulo, n. 114, p. 179-195, 2001.

RIBEIRO, A. E.; GUIMARÃES, I. F.; SILVA, S. E. C. Aulas de português na formação de engenheiros: expectativas e concepções de alunos e professores de instituição pública em Minas Gerais. Scripta, v. 16, n. 30, p. 117-136, 2012.

STREET, B. Multiple literacies and multi-literacies. In: BEARD, R. et al. (Eds.). The SAGE Handbook of Writing Development. Londres: SAGE, p. 137-150, 2009.

UFRN. Projeto Pedagógico do Curso de Bacharelado em Ciência e Tecnologia. Natal, 2017. Disponível em: https://sigaa.ufrn.br/sigaa/public/curso/ppp.jsf?lc=pt_BR\&id=10320810. Acesso em 10 jan. 2019.

UFERSA. Projeto Pedagógico do Curso de Bacharelado em Ciência e Tecnologia. Mossoró, 2010. Disponível em: https://cet.ufersa.edu.br/apresentacao/. Acesso em: 10 jan. 2019. 